GUANGCHUAN YANG, Ph.D. ${ }^{1}$

E-mail: yanggc1986@gmail.com

DAOBIN WANG, Ph.D. ${ }^{2}$

(Corresponding author)

E-mail: wangdaobin05@163.com

XUESONG MAO, Ph.D. ${ }^{3}$

E-mail: xsmao@wust.edu.cn

${ }^{1}$ Institute of Transportation Research and Education

North Carolina State University

909 Capability Drive, Raleigh, NC 27606, U.S.

2 School of Automobile and Traffic Engineering

Wuhan University of Science and Technology

947 Heping Road, Wuhan, Hubei 430081, China

${ }^{3}$ School of Information Science and Engineering

Wuhan University of Science and Technology

947 Heping Road, Wuhan, Hubei 430081, China
Traffic in the Cities Original Scientific Paper Submitted: 12 Oct. 2019 Accepted: 25 May 2020

\title{
MODELLING THE MODAL SHIFT EFFECTS OF CONVERTING A GENERAL TRAFFIC LANE INTO A DEDICATED BUS LANE
}

\begin{abstract}
This paper presents an analytical framework for evaluating the performance of dedicated bus lanes. It assumes that under a designated travel demand, the traffic volume on a corridor changes with the modal shifts. The modal shift affects the operations of both bus traffic and car traffic and eventually, an equilibrium bus share ratio that maximizes the performance of the corridor will be reached. Microsimulation modelling is employed to assess the traffic operations under various demand levels and bus share ratios. The results show that converting a general lane into a bus lane significantly reduces bus delay. For car traffic, the overall trend is that delay increases after converting a general lane to a bus lane. In addition, delay decreases with the increase of bus share ratio. Nevertheless, when bus share ratio reaches 0.6 (demand less than 10,000 passengers per hour, pph; or 0.8 when demand increases up to $14,000 \mathrm{pph}$ ), there is no significant difference in delay between the two scenarios. The identified bus share ratios have the potential to direct the development of bus lane warrants. Finally, this research recommends that the Transportation Demand Management (TDM) strategies shall be developed to stimulate the modal shifts towards the identified optimal bus share ratio.
\end{abstract}

\section{KEY WORDS}

bus lane; Mogridge's Conjecture; modal shift; microsimulation; delay; bus lane warrants;

\section{INTRODUCTION}

A dedicated bus lane has the potential to decrease bus travel time and increase schedule adherence, since it eliminates the interactions between buses and passenger cars at both road segments and signalized intersections. In practice, stimulating a modal shift from private vehicles towards buses is a desirable strategy to alleviate urban congestion problems. At present, various patterns of bus lanes have been implemented in several Asian, European and American cities to improve the Level of Service (LOS) of buses, thus achieving the goal of attracting more passengers to use buses and eventually, tackle the urban traffic congestion problems [1-6]. A handful of studies have been carried out to study or verify the impacts of a dedicated bus lane, such as the equilibrium mechanism within a roadway system after the installation of a bus lane [7, 8], and the design and evaluation of dedicated bus lanes [9-14]. These studies, in general, concluded that a bus lane could improve the operation of buses, and bring considerable benefits to both passengers and the society with the occurrence of modal shifts.

Nevertheless, the implementation of mode switching strategies such as a dedicated bus lane requires proper evaluation of the proposed strategy on the travel behaviour changes and traffic operations. After converting a general lane to an exclusive bus 
lane, the capacity of the remaining lanes will be degraded, which tends to result in higher congestion and lower travel speed on the capacity-reduced general lanes, particularly when the modal shift is insignificant. Therefore, one of the most challenging issues for installing a dedicated bus lane is whether this would bring about a significant impact on general traffic, since deviations on estimating traffic flow assignment to the bus lane and general lanes may lead to inefficient use of road space resources [15]. Therefore, this study aims to investigate the interactions between two competitive travel modes in the roadway system, and accordingly determine the ideal bus share which could guarantee the efficiency of the roadway system.

The remainder of this paper is organized as follows: first, there is a brief literature review regarding the performance assessment of bus lanes; after that, modelling the modal shift effects based on economics principles is given; this is followed by the traffic operation performance assessment of dedicated bus lane under various traffic demands and bus share ratio scenarios based on microsimulation modelling; and finally, major findings and discussions are presented.

\section{LITERATURE REVIEW}

To date, there have been a number of studies that employed empirical and/or analytical approach(es) to evaluate the performance of dedicated bus lanes. In the early 1980s, Sheffi [7] made a simple equilibrium analysis based on a Logit mode choice model and a typical volume-delay curve to examine the effect of converting an existing freeway lane to a dedicated bus lane, and concluded that only under extreme road congestion would the benefits of bus lane be realized. However, this study was focused on freeways rather than urban arteries, where free-flow speed is much higher and traffic flow density is usually lower than that of urban roads. Later, Hounsell and McDonald [9] and Shalaby and Soberman [10] investigated the impact of with-flow bus lanes on travel times using "before and after observations" and indicated that ridership generally increases after introducing a bus lane. Similarly, St. Jacques and Levinson [11] presented a procedure for estimating the travel speeds and capacities of differential bus lanes along urban arterials; relationships for estimating bus speeds were developed which considered the variables that may affect bus lane speeds and capacities, e.g. bus service frequency, bus stops per mile, dwell times and service patterns, signal control strategies, traffic flow conditions, etc. Gan et al. [16] studied the overall average person travel time under scenarios of with and without a bus lane, based on which they developed an operational performance and decision model to justify whether or how to design bus lanes on urban arterials. Tsamboulas [17] identified the impacts of an exclusive bus lane to all stakeholders and then applied a cost-benefit analysis approach to evaluate the net benefits of a bus lane in monetary indices. One of the major findings was that exclusive bus lane facilities may benefit low-income travellers while imposing costs on high-income travellers. Currie et al. [15] and Mesbah et al. [18] studied the implementation and evaluation of road space re-allocation. They indicated that under substantial service frequencies and passenger volumes, the allocation of space to public transport minimizes negative traffic impacts (i.e. avoids traffic squeezed into the remaining lane) could improve the overall management of road space. $\mathrm{Li}$ and $\mathrm{Ju}$ [19] presented a point-queue model to reflect the interactions of cars and buses under two scenarios: networks with and without dedicated bus lanes. A comprehensive impacts analysis and evaluation of dedicated bus lanes on travel behaviour were performed, including traveller's mode choices, departure time choices, and route choices. Yao et al. [20] proposed a bi-level programming model to analyse the operations of exclusive bus lanes under variable bus frequencies. Modelling results indicated that the benefits of bus lanes tended to be greater with increased traffic demand; nevertheless, oversetting of bus lanes resulted in reduced operating efficiency of the entire transportation system. Zhao and Zhou [21] presented a dynamic exclusive bus lane configuration, in which the exclusive bus lane can be dynamically used for the left turn buses and the opposing through buses during various periods of a signal cycle. In comparison with the traditional bus lane configuration, it was found that the dynamic exclusive bus lane considerably reduced the average person delay when traffic demand is larger than 900 vehicle per hour (vph).

In comparison with the empirical and analytical approaches that require a large number of field-collected traffic performance data, microsimulation modelling approach has the advantages such as the flexibility of assessing various bus lane configurations under different traffic demand levels. An early simulation study performed by Shalaby [22] 
employed TRANSYT-7F simulator to evaluate the performance of reserved bus lanes in an urban arterial. The simulation results indicated that the bus lanes improved the operation of buses while deteriorating the performance of adjacent general traffic. Waterson et al. [23] pointed out that the effect of implementing bus priority measures depends on the characteristics of the local travellers, and further proved that implementing too strong bus priority schemes might not benefit the public transport. Arasan and Vedagiri [24] studied and quantified the possible impacts of the provision of an exclusive bus lane under heterogeneous traffic condition using a simulation model, based on which they identified the maximum permissible $\mathrm{V} / \mathrm{C}$ ratio that can guarantee the designated Level of Service, and accordingly estimated the probable shift from private car towards public transport. Zhu et al. [25] conducted a before-after analysis of exclusive bus lanes using VISSIM, and concluded that the operational efficiency of the entire transportation system was improved with the deployment of exclusive bus lanes, particularly for the median type bus lane. Similarly, Tu et al. [26] compared the operations of three bus lane types (i.e. exclusive bus lane, bus priority lane, and ordinary lane) using PARAMICS. The results suggested that although all the bus lane types can significantly improve the bus service, their negative impacts on general traffic were also not negligible. Therefore, the selection of bus lane types needs to consider the main road traffic volume as well as the number of passengers on the bus. Ben-Dor et al. [27] employed MATSim software to assess the impact of dedicated bus lane on urban road traffic and concluded that dedicated bus lanes resulted in a 20\% increase in public transport use under a relatively high level of congestion.

These studies, in general, did not fully consider the effects of modal split on the traffic volume. According to the utility-based mode choice theory, an individual passenger usually prefers to choose a mode which has the maximum utility $[28,29]$. Converting a general lane into a dedicated bus lane will undoubtedly change the utilities of bus traffic and general traffic, and consequently result in potential modal shifts between the two competitive modes $[30,31]$. Therefore, when analysing the impact of bus priority measures such as a dedicated bus lane, it is necessary to incorporate the effects of modal split on speed-flow relationships, particularly for urban arterials.
Currently, there is limited study that endeavours to estimate the potential modal shift effects resulting from bus priorities. Vedagiri and Arasan [32] estimated the probable modal shifts after the installation of a dedicated bus lane on urban arterials. The core techniques of their study are SP/RP survey-based mode choice model and traffic micro-simulation. A mode choice probability curve to depict the possible shift from car to bus was developed taking the difference in the travel times of the two modes. Zuo et al. [33] attempted to identify the ideal bus share within roadway system via analytical modelling. However, it was based on some unrealistic assumptions without consideration of the user equilibrium principle and signal control. Travel speed was assumed to be the only determinant of the modal shift, which cannot capture the mode choice mechanism. Likewise, Idris et al. [3] investigated the commuters' mode switching behaviour and developed the econometric choice modes to forecast the modal shift towards public transit. This study aims to evaluate the impacts of alternative transit service designs on travel behaviour to precisely estimate the transit ridership. Wang et al. [34, 35] applied a binary logistic analysis method for assessing the impacts of modal shifts from general traffic modes to Bus Rapid Transit (BRT). This study indicated that the traveller's demographic and socioeconomic attributes and trip-related attributes would be statistically significant in influencing the modal shifts to BRT, and travel time saving is the primary fact that attracts the modal shift. Yao et al. [36] developed a bi-modal user equilibrium model, which incorporated the travellers' risk-adverse behaviour for evaluating exclusive bus lanes. Based on numerical examples, the authors revealed that road degradation level, travellers' risk-aversion level, and the uncertainty of the bus waiting time affected the user equilibrium results. Zheng et al. [37] employed a simulation approach to determine the optimal space share between the modes in service. The impact of a bus lane on mode usage was taken into account to aggregated mode shift phenomena under changes in the layout of dedicated bus lanes. The simulation results indicated that an optimal and efficient space share could minimize the total travel cost for all users.

Nevertheless, from the review of the state-ofthe-practice, very limited studies or guidelines were found regarding the traffic volume and bus share ratio condition(s) under which a general lane should 
be converted into a dedicated bus lane. On the basis of the state-of-the-practice reviewed above, this study will first focus on capturing the interactions between bus traffic and general traffic, then employ microsimulation modelling approach to evaluate the impacts of converting a general lane into a dedicated bus lane; and eventually, identify the optimum bus modal split ratio that would optimize the roadway system.

\section{MODAL SHIFTS MODELLING}

\subsection{Equilibrium mechanism of roadway system}

In transportation economics, there exists a Downs-Thomson paradox, which is described as follows: "An increase in road capacities, by causing shifts from public transit to private transport, could lead to a new traffic equilibrium where total transport costs are higher" [38]. Based on Downs-Thomson paradox, Mogridge [39] indicated that: "A decrease in road capacities, or better, an increase in mass transit capacity, could shift car users to buses and can therefore decrease total travel times". This statement was defined as "Mogridge's Conjecture", which reflected the equilibrium mechanism between bus and car modes before and after converting a general lane into a bus lane.

The bi-modal equilibrium after converting a general lane into a dedicated bus lane is demonstrated in Figure 1. When total travel demand is fixed, road traffic volume will be affected by the proportion of bus mode. For heterogeneous traffic operation situation (i.e. no bus lane), the initial equilibrium occurs

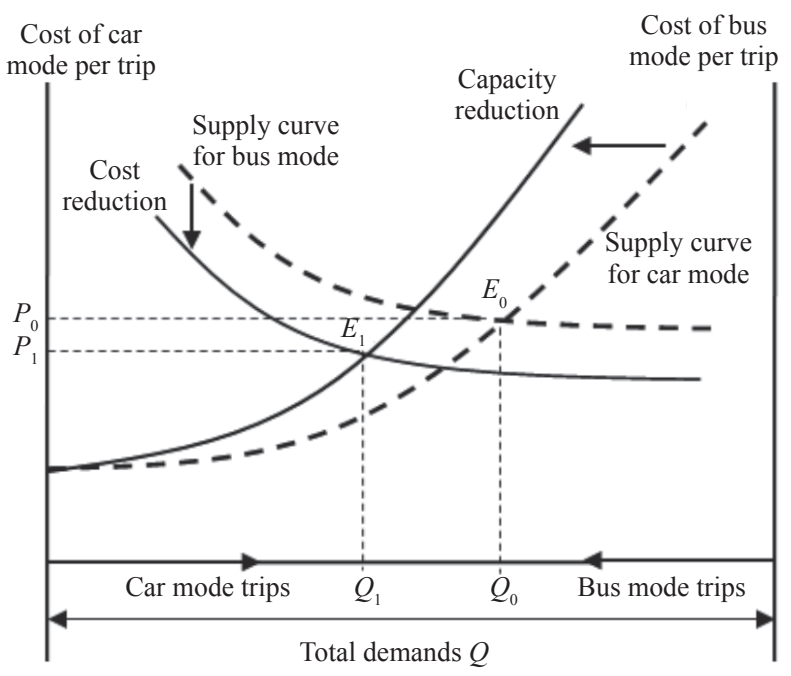

Figure 1 -Bi-modal equilibrium after converting a general lane into a dedicated bus lane at point $E_{0}$, where bus mode and car mode have the same travel cost $P_{0}$; the modal split of bus and car are $\left(Q-Q_{0}\right) / Q$ and $Q_{0} / Q$, respectively. By converting a general lane into a dedicated bus lane, the capacity of general lanes will be reduced, and consequently make a sharper supply curve. Meanwhile, cost of bus travel will be reduced due to the improved traffic conditions; accordingly, a new equilibrium is established at point $E_{1}$, where travel cost decreases to $P_{1}$. With fixed total demand, car trips decrease from $Q_{0}$ to $Q_{1}$, and the modal shift effect could be described as $\left(Q_{0}-Q_{1}\right) / Q$.

\subsection{Assumptions}

To facilitate the modelling process, the following assumptions are presented here:

1) Total passenger trip volume (or total passenger demand) $Q_{p}$ remains unchanged before and after the installation of the bus lane (i.e. no generated passenger demand due to the improved traffic condition);

2) Traffic flow on the road segment contains two modes: general traffic, $\left(q_{c}\right)$, and bus traffic, $\left(q_{b}\right)$; after converting a general lane to a dedicated bus lane, general traffic runs on the remaining general lanes, and buses run on the dedicated bus lane;

3) Fixed-time control signalized intersections during peak hours;

4) Travel speed as a function of road traffic volume.

\subsection{Relationship between corridor traffic volume and bus share ratio}

\section{Scenario one: Heterogeneous traffic without bus lane}

Under this scenario, bus traffic flow and general traffic flow could be treated as a whole by converting buses into passenger car units (pcu). A larger bus share means less traffic flow on the corridor and accordingly results in higher travel speed and fewer delays of the roadway system. The relationship between bus share ratio and traffic volume is depicted in Equation 1.

$Q=Q_{c a r}+Q_{b u s}=\frac{Q_{p} \cdot(1<\delta)}{P_{c}}+\frac{Q_{p} \cdot \delta \cdot f_{b}}{P_{b}}$

where $Q$ is the total traffic volume on the corridor (pcu/h); $Q_{c a r}$ and $Q_{b u s}$ are car traffic volume and bus traffic volume on the corridor (vehicle per hour, vph), respectively; $Q_{p}$ is the total passenger demand on the corridor (passenger per hour, pph); $P_{c}$ and $P_{b}$ 
are the average occupancy of car and bus, respectively; $\delta$ is the percentage of passengers choosing bus; $f_{b}$ is the passenger car equivalent for bus, which could be set as 2.5 .

\section{Scenario two: Separated traffic with bus lane}

After converting a general lane into a bus lane, the travel speed of general traffic would be affected by the proportion of bus mode share; a lower bus share ratio will result in a higher volume-capacity ratio for the general traffic on the capacity-reduced general lanes, consequently leading to lower travel speed and larger control delay at signalized intersections. In comparison, since the occupancy of a bus is usually much larger than the one of a passenger car, the travel speed of buses may not be as sensitive to bus mode share as general traffic. In this scenario, the relationships between bus share ratio and traffic volume on general lanes and bus lane are depicted in Equations 2 and 3, respectively.

$Q_{c a r}=\frac{Q_{p} \cdot(1-\delta)}{P_{c}}$

$Q_{b u s}=\frac{Q_{p} \cdot \delta}{P_{b}}$ (in number of vehicles), or

$Q_{b u s}=\frac{Q_{p} \cdot \delta \cdot f_{b}}{P_{b}}$ (in pcu)

\subsection{Impacts of bus share on intersection delays}

The interactions between signal control at the intersections and route choices in the urban road network are a non-negligible factor during traffic assignment processes [40]. Conventional approaches, however, usually treat each problem independently, assuming that they are unaffected by each other: traffic signals are set under fixed volumes, whereas travel demands are assigned to routes assuming fixed signal setting [41]. Such approaches might not exactly capture the real-world traffic operations, and thus might be appropriate for equilibrium traffic assignment modelling, because traffic volumes and signal setting are mutually interdependent, as shown in Figure 2.

In fact, control delays at signalized intersections are directly affected by the traffic volume of intersection approaches. Since modal shifts between the two modes would influence the total traffic volume, to improve the accuracy of equilibrium traffic assignment, it is necessary to find the relationship that inherently captures the mutual interaction between traffic volume (i.e. bus share ratio) and signal delays at intersections.

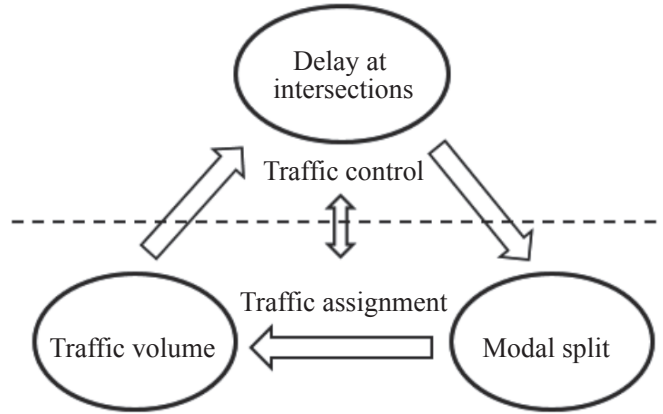

Figure 2 - Mutual interactions between control delay and route/mode choice

Even though many studies focused on integrating signal timing/delay and traffic re-assignment on the basis of user equilibrium principle [42-44], very limited studies considered explicitly the impacts of bus priorities on modal shifts. Aiming at this problem, an exploratory analysis of relationships between bus share and delays at intersections was performed based on the Highway Capacity Manual (HCM) method. The average control delay per vehicle in the HCM model is described as follows [45].

$$
\begin{aligned}
& d=d_{1}(P F)+d_{2} \\
& d_{1}=\frac{0.5 C\left(1-\frac{g}{c}\right)^{2}}{1-\left[\min (1, X) \frac{g}{c}\right]} \\
& d_{2}=900 T\left[(X-1)+\sqrt{\left.(X-1)^{2}+\frac{8 k I X}{c T}\right]}\right.
\end{aligned}
$$

In the HCM model, the degree of saturation (parameter $X$; or more specifically, traffic volume) is the determinant of control delays. For heterogeneous traffic conditions, the average control delay of general traffic equals the bus traffic; a larger bus share will lead to a smaller control delay. For separated traffic condition, since traffic volume on the dedicated bus lane is usually very slight, consequently the average control delay of bus traffic would not be significantly influenced by bus traffic share ratio, and generally, it could be treated as uniform control delay. In contrast, however, the delay of general traffic will be significantly affected by the bus share ratio due to the reduction of capacity; a lower bus share ratio tends to lead to a larger control delay.

\subsection{Impacts of bus share on travel speed}

The widely used U.S. Bureau of Public Roads (BPR) function described the relationship between link travel time and volume as:

$T_{q}=T_{0}\left[1+\alpha\left(\frac{q}{c}\right)^{\beta}\right]$ 
where $T_{q}$ is the average travel time for a vehicle; $T_{0}$ is the free-flow travel time; $c$ is the link capacity; $q$ is the link traffic volume; $\alpha, \beta$ are parameters. Equation 7 can also be written as:

$$
V_{q}=\frac{V_{0}}{1+\alpha\left(\frac{q}{c}\right)^{\beta}}
$$

In reality, the operational characteristics of cars and buses are different; the speed-flow relationships of buses and cars are therefore established separately.

$$
\begin{aligned}
V_{q}^{b} & =\frac{V_{0}^{b}}{1+\alpha\left(\frac{q}{c}\right)^{\beta}} \\
V_{q}^{c} & =\frac{V_{0}^{c}}{1+\alpha\left(\frac{q}{c}\right)^{\beta}}
\end{aligned}
$$

where $V_{q}^{b}$ and $V_{q}^{c}$ are average travel speeds of bus and car when road volume is $q ; V_{0}^{b}$ and $V_{0}^{c}$ are free-flow speeds of bus and car, respectively. This research employed 40 kilometres per hour $(\mathrm{kph})$ for $V_{0}^{b}$, and $50 \mathrm{kph}$ for $V_{0}^{c}$ as the default free-flow speeds, which are later used for calibrating the microsimulation model.

In real-world conditions, the actual travel speed is affected by the delays at signalized intersections and bus stops. The actual travel speed of bus and car could be rewritten as:

$$
\begin{aligned}
& V_{\text {travel }}^{b}=\frac{L}{\sum_{i=1}^{n} \frac{L_{i}}{V_{q}^{b}+\sum_{i=1}^{n} d_{i}^{b}+\sum_{j=1}^{m} d_{j}}} \\
& V_{\text {travel }}^{c}=\frac{L}{\sum_{i=1}^{n} \frac{L_{i}}{V_{q}^{c}}+\sum_{i=1}^{n} d_{i}^{c}}
\end{aligned}
$$

where $V_{\text {travel }}^{b}$ and $V_{\text {travel }}^{c}$ represent the actual travel speed of bus and car; $L$ is the length of the road; $L_{i}$ is the length of each link between two intersections; $V_{q}^{b}$ and $V_{q}^{c}$ are average travel speeds of bus and car when road volume is $q ; d_{i}^{b}$ and $d_{i}^{c}$ represent signal control delays of bus and car; $d_{j}$ represents delay at bus stops; $n$ and $m$ represent the number of signals and bus stops of the link.

\section{MICROSIMULATION MODELLING}

To reveal the impact of bus share ratios on traffic operations and determine the optimum bus share ratio for installing a dedicated bus lane, this paper employed VISSIM microsimulation modelling approach to evaluate the performance of a dedicated bus lane under various demand levels and bus share ratio scenarios.

\subsection{Simulation network}

The simulation network was designed as a six traffic lane urban signalized arterial (three lanes per direction), which represents the most commonly used urban arterial configuration in the China metropolis. The simulated corridor was coded in PTV VISSIM 9.0 microsimulation package; it was approximated three kilometres in length with three signalized intersections and two bus stops in between, as illustrated in Figure 3. The distances between adjacent signals were designed as 1,030 metres, and each bus stop was located 160 metres downstream of the signalized intersection. Besides, both bus stops were far-side off-line type. The roadway network, vehicle kinematic characteristics and driver behaviour parameters have been calibrated based on the actual roadway geometry features and traffic data collected by portable video cameras placed at the first intersection of the simulated corridor [31].

To capture the operation features of bus traffic, this research employed VISSIM "Bus Static" component to simulate the bus stopping behaviour at bus stations as well as passenger alighting and boarding

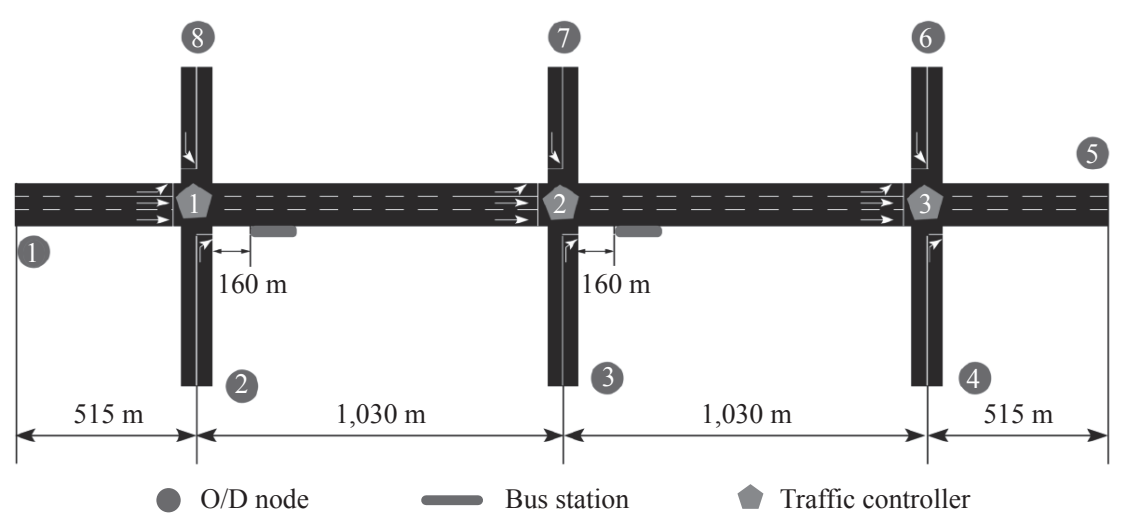

Figure 3 - Illustration of the roadway network for the simulation experiment 
activities; the stopping time at a bus station was set as random. Specifically, this research designed two bus stations using VISSIM "Public Transport Stops" module, and developed the bus routes through the "Public Transport Lines" module. Then, this research coded the bus line(s) that would stop at each station based on the field observed route of each bus line. Finally, each bus line was assigned a departure interval to simulate the scheduling of the bus line. In addition, by changing the departure intervals, the total bus traffic volume on this corridor could be amended. Vehicle travel time detectors were placed between Node 1 and Node 5 to collect the travel time and delay of cars and buses, which are eventually employed as Measurements of Effectiveness (MOEs) for assessing the impacts on converting a general lane into a dedicated bus lane on traffic operations under various travel demand levels and bus modal splits.

\subsection{Simulation scenarios}

Being limited by the availability of real-world passenger flow and mode choice data (i.e. actual occupancies of each bus and private car), this microsimulation modelling employed a numerical-based study to test the operational performance of dedicated bus lane under various travel demand and modal split scenarios. In accordance with the typical traffic operational features in China, this paper assumes that the average occupancies of a bus and a private car are 60 passengers and 3 passengers, respectively [31]. The baseline total passenger traffic demand on the corridor was assumed to be $10,000 \mathrm{pph}$, which represented the typical travel demand of the China metropolis during the peak period. The desired speed distributions of car and bus were also calibrated to represent the real-world operation features. Then, a sensitivity analysis of passenger traffic demand was conducted by decreasing and increasing the baseline demand by $20 \%$ and $40 \%$, respectively. Based on Equations 1-3, the total traffic volume in the corridor under various bus share ratios could be estimated, as listed in Table 1. Based on Assumption 2, for no bus lane scenario, the traffic volume in the corridor under each bus share ratio equals the sum of passenger car volume and bus volume. In comparison, for the bus lane scenario, the traffic volume on general lanes and bus lane equal the passenger car volume and bus volume, respectively.

In real-world condition, it has been a typical strategy to use fixed-time coordinated signal control scheme at a signalized corridor during peak period. With this consideration, the microsimulation modelling utilized a fixed-time moderate length of cycle

Table 1 - Total traffic volume on the simulated corridor under various bus share ratio scenarios

\begin{tabular}{|c|c|c|c|c|c|c|c|c|c|}
\hline \multirow{2}{*}{$\begin{array}{l}\text { Travel demand } \\
\text { [pph] }\end{array}$} & \multirow{2}{*}{$\begin{array}{l}\text { Vehicle } \\
\text { type }\end{array}$} & \multicolumn{8}{|c|}{ Total traffic volume on the corridor under various bus share ratios [vph] } \\
\hline & & $20 \%$ & $30 \%$ & $40 \%$ & $50 \%$ & $60 \%$ & $70 \%$ & $80 \%$ & $90 \%$ \\
\hline \multirow{2}{*}{6,000} & Car & 1,600 & 1,400 & 1,200 & 1,000 & 800 & 600 & 400 & 200 \\
\hline & Bus & 20 & 30 & 40 & 50 & 60 & 70 & 80 & 90 \\
\hline \multirow{2}{*}{8,000} & Car & 2,133 & 1,867 & 1,600 & 1,333 & 1,067 & 800 & 533 & 267 \\
\hline & Bus & 27 & 40 & 53 & 67 & 80 & 93 & 107 & 120 \\
\hline \multirow{2}{*}{10,000} & Car & 2,667 & 2,333 & 2,000 & 1,667 & 1,333 & 1,000 & 667 & 333 \\
\hline & Bus & 33 & 50 & 67 & 83 & 100 & 117 & 133 & 150 \\
\hline \multirow{2}{*}{12,000} & Car & 3,200 & 2,800 & 2,400 & 2,000 & 1,600 & 1,200 & 800 & 400 \\
\hline & Bus & 40 & 60 & 80 & 100 & 120 & 140 & 160 & 180 \\
\hline \multirow{2}{*}{14,000} & Car & 3,733 & 3,267 & 2,800 & 2,333 & 1,867 & 1,400 & 933 & 467 \\
\hline & Bus & 47 & 70 & 94 & 117 & 140 & 163 & 187 & 210 \\
\hline
\end{tabular}


Yang G, Wang D, Mao X. Modelling the Modal Shift Effects of Converting a General Traffic Lane into a Dedicated Bus Lane

Table 2 - Signal timing information of the three intersections in the simulated corridor

\begin{tabular}{|c|c|c|c|c|c|}
\hline Intersection \# & Phase number & Split [s] & Green $[\mathrm{s}]$ & Yellow $[\mathrm{s}]$ & All-red [s] \\
\hline \multirow{7}{*}{ Intersection 1} & 1 & 30 & 27 & 3 & 1 \\
\hline & 3 & 30 & 27 & 3 & 1 \\
\hline & 6 & 30 & 27 & 3 & 1 \\
\hline & \multirow{2}{*}{ Phasing sequence: } & \multirow{2}{*}{\begin{tabular}{|l}
$|1| 3$ \\
$6 \mid$
\end{tabular}} & & \multicolumn{2}{|l|}{ Cycle [s]: 120} \\
\hline & & & & \multicolumn{2}{|l|}{ Offset [s]: 0} \\
\hline & \multicolumn{3}{|l|}{ Reference phase: 6} & \multicolumn{2}{|c|}{ Refer to: Begin of green } \\
\hline & Phasing diagram: & \multicolumn{4}{|c|}{ 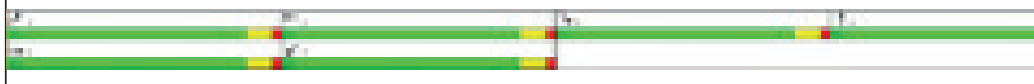 } \\
\hline \multirow{7}{*}{ Intersection 2} & 1 & 30 & 27 & 3 & 1 \\
\hline & 3 & 30 & 27 & 3 & 1 \\
\hline & 6 & 30 & 27 & 3 & 1 \\
\hline & \multirow{2}{*}{ Phasing sequence: } & \multirow{2}{*}{$\begin{array}{l}1 \mid 3 \\
6 \mid\end{array}$} & & \multicolumn{2}{|l|}{ Cycle [s]: 120} \\
\hline & & & & \multicolumn{2}{|l|}{ Offset [s]: 10} \\
\hline & \multicolumn{3}{|l|}{ Reference phase: 6} & \multicolumn{2}{|c|}{ Refer to: Begin of green } \\
\hline & Phasing diagram: & \multicolumn{4}{|c|}{ airis } \\
\hline \multirow{7}{*}{ Intersection 3} & 1 & 30 & 27 & 3 & 1 \\
\hline & 3 & 30 & 27 & 3 & 1 \\
\hline & 6 & 30 & 27 & 3 & 1 \\
\hline & \multirow{2}{*}{ Phasing sequence: } & \multirow{2}{*}{$\begin{array}{l}1 \mid 3 \\
6 \mid\end{array}$} & & \multicolumn{2}{|l|}{ Cycle [s]: 120} \\
\hline & & & & \multicolumn{2}{|l|}{ Offset [s]: 20} \\
\hline & \multicolumn{3}{|l|}{ Reference phase: 6} & \multicolumn{2}{|c|}{ Refer to: Begin of green } \\
\hline & Phasing diagram: & Pi & & & \\
\hline
\end{tabular}

(i.e. $120 \mathrm{sec}$ ) for numerical demonstration. Signal timing information for the three intersections is presented in Table 2.

\section{RESULTS}

\subsection{Simulated delay profiles for each vehicle type}

A total of 80 simulation scenarios (i.e. five demand levels multiplied by eight bus share ratios for both with-bus-lane and without-bus-lane conditions) were designed to reveal the impact of converting a general lane into a dedicated bus lane on traffic operations under various demand levels and bus share ratios. Each simulation scenario was run ten times to minimize the potential stochastic errors caused by simulation. Simulated delays for car and bus before and after converting a general lane into a bus lane are illustrated in Figure 4.
Simulation results indicate that in general, delay profiles display a decreasing trend with the increase of bus share ratio regardless of with or without a bus lane. This trend applies for all the demand levels, which is mainly due to the occupancy of a bus vehicle being significantly larger than the one of a passenger car. At each demand level, a higher bus share ratio means fewer vehicles running on the corridor. In terms of the impacts on different vehicle types, for bus traffic, significant reductions in delay were found for all the demand levels, particularly at a lower bus share ratio. In comparison, the impacts on car traffic tend to be more complex. Despite some fluctuations in the simulated delay profiles, the overall trend is that the delay of car traffic increased after converting a general lane into a bus lane. Under each demand level and for each vehicle type, the changes in delay reached an equilibrium at a designated bus share ratio . 


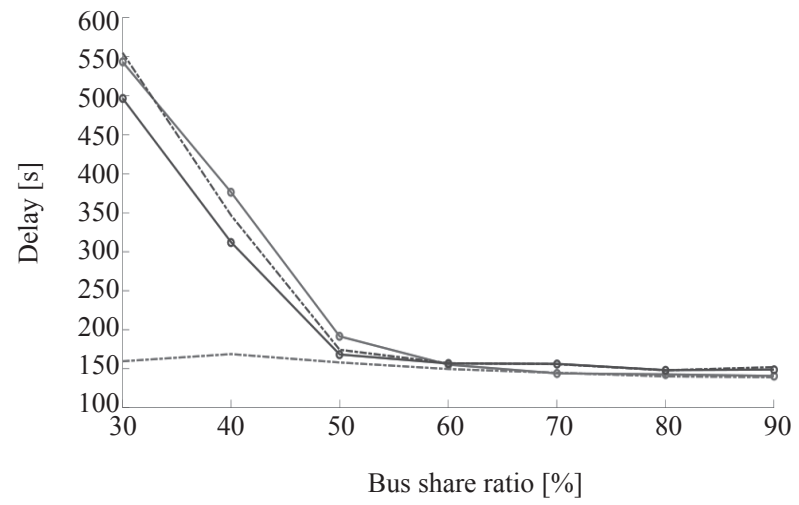

a) Demand $=6,000 \mathrm{pph}$

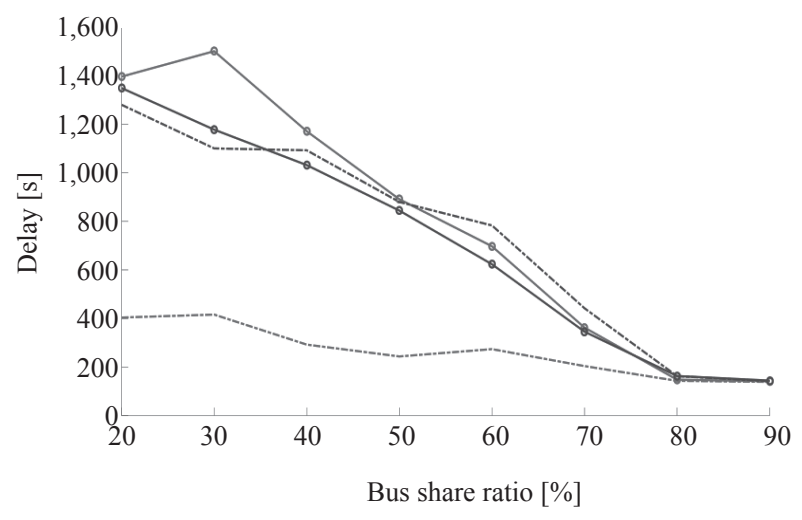

c) Demand $=10,000 \mathrm{pph}$

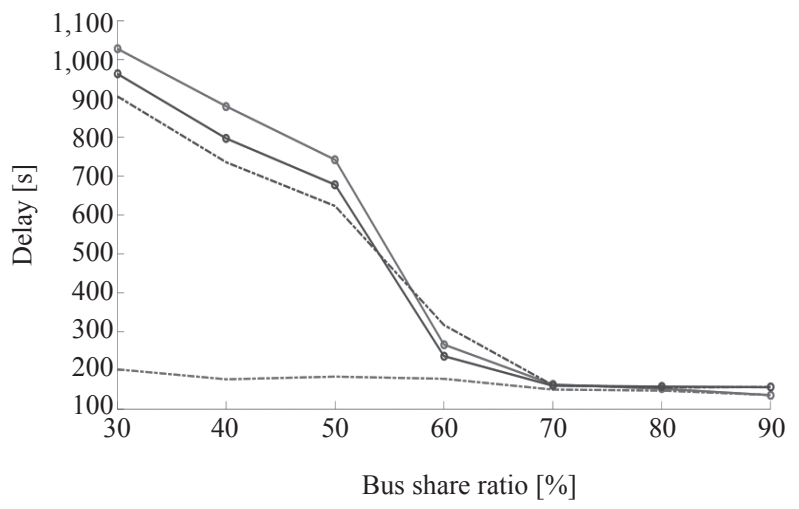

b) Demand $=8,000 \mathrm{pph}$

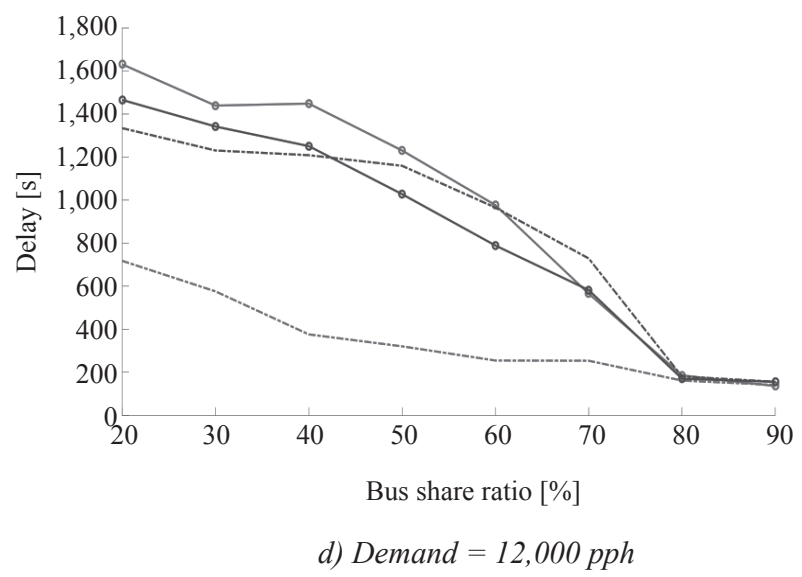

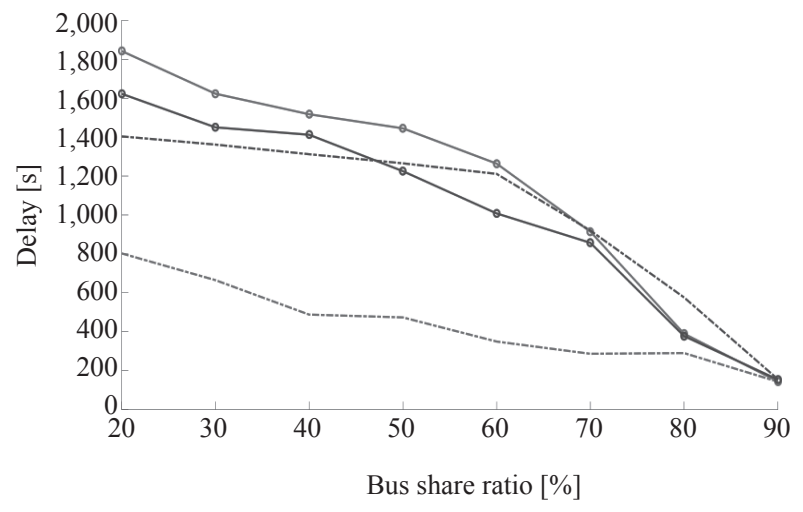

e) Demand $=14,000 \mathrm{pph}$

-.- Bus (bus lane) $\quad-$ Bus (no bus lane) -.- Car (bus lane)

- Car (no bus lane)

Figure 4 - Comparisons of delays of car traffic and bus traffic under various bus share ratios

\subsection{Average passenger delay on the corridor}

In addition to the delay profiles for the two vehicle types, this research further investigated the impacts of converting a general lane to a dedicated bus lane on the average passenger delay, which is eventually used to determine the optimal bus share ratio for installing a dedicated bus lane. The average passenger delay is calculated as follows:

$$
D_{\text {Passenger }}^{\text {Avg. }}=\frac{D_{\text {bus }} \cdot Q_{p} \cdot \delta+D_{\text {car }} Q_{p} \cdot(1-\delta)}{Q_{p}}
$$

where:

$D_{\text {Passenger }}^{\text {Avg. }}$ average passenger delay;

$D_{\text {bus }} \quad$ - average delay per bus;

$D_{\text {car }} \quad$ - average delay per car;

$Q_{p} \quad-$ total demand in pph;

$\delta \quad-$ proportion of passengers choosing bus. 
Yang G, Wang D, Mao X. Modelling the Modal Shift Effects of Converting a General Traffic Lane into a Dedicated Bus Lane

Table 3 - Summary of average passenger delay under various demand levels and bus share ratios

\begin{tabular}{|c|c|c|c|c|c|c|c|c|c|}
\hline \multirow{2}{*}{ Demand } & \multirow{2}{*}{ Scenario } & \multicolumn{8}{|c|}{ Average passenger delay under various bus share ratios $[\mathrm{s}]$} \\
\hline & & $20 \%$ & $30 \%$ & $40 \%$ & $50 \%$ & $60 \%$ & $70 \%$ & $80 \%$ & $90 \%$ \\
\hline \multirow{2}{*}{6,000} & No bus lane & $\mathrm{n} / \mathrm{a}$ & 510.5 & 337.6 & 179.9 & 155.9 & 147.8 & 143.9 & 141.6 \\
\hline & Bus lane & $\mathrm{n} / \mathrm{a}$ & 436.3 & 275.4 & 166.2 & 152.6 & 148.2 & 141.8 & 140.5 \\
\hline \multirow{2}{*}{8,000} & No bus lane & $\mathrm{n} / \mathrm{a}$ & 983.0 & 830.2 & 710.1 & 254.4 & 162.5 & 153.7 & 138.1 \\
\hline & Bus lane & $\mathrm{n} / \mathrm{a}$ & 694.6 & 512.2 & 403.4 & 233.5 & 153.8 & 149.3 & 138.3 \\
\hline \multirow{2}{*}{10,000} & No bus lane & $1,358.9$ & $1,275.1$ & $1,087.8$ & 867.9 & 667.8 & 357.2 & 150.7 & 141.7 \\
\hline & Bus lane & $1,105.2$ & 895.3 & 772.6 & 561.7 & 477.5 & 275.1 & 146.8 & 138.6 \\
\hline \multirow{2}{*}{12,000} & No bus lane & $1,498.6$ & $1,371.3$ & $1,330.1$ & $1,129.2$ & 901.8 & 570.4 & 182.4 & 137.8 \\
\hline & Bus lane & $1,211.3$ & $1,034.2$ & 875.7 & 740.0 & 538.9 & 396.2 & 165.2 & 142.5 \\
\hline \multirow{2}{*}{14,000} & No bus lane & $1,666.7$ & $1,502.1$ & $1,454.4$ & $1,335.1$ & $1,161.6$ & 897.1 & 387.4 & 145.8 \\
\hline & Bus lane & $1,283.5$ & $1,152.7$ & 982.6 & 869.5 & 694.3 & 476.7 & 347.6 & 144.7 \\
\hline
\end{tabular}

Note: $n / a$ means no available data. This is because the minimum bus traffic should be set as 30 veh/h in VISSIM 9.0

A summary of the average passenger delay under various demand levels and bus share ratios is listed in Table 3.

The results reveal that the average passenger delays decreased after converting a general lane into a bus lane for all the demand levels. The reductions in delay are particularly significant for a relatively higher demand level (e.g. higher than 8,000 pph). However, it is necessary to point out that when bus share ratio reaches a certain level, the differences in delay between bus lane and no bus lane conditions are not significant. These bus share ratios are approximately $60 \%$ when the demand is less than $10,000 \mathrm{pph}$, and $80 \%$ when the demand is larger than $10,000 \mathrm{pph}$.

\section{DISCUSSION}

Previous studies have pointed out that with successive reductions in general traffic flow and a modal shift to bus travel, it would be possible to improve the overall journey speed of all travellers, both those left in the car and those switching to the bus [2, 3, $6,8,32,35,39]$. Nevertheless, in current practice there is limited research in identifying the optimal bus share ratio that can effectively use road space. In this regard, this paper first investigated the effects of converting a general lane to a bus lane in corridor traffic operation. The findings from this research are consistent with the aforementioned studies. Then, this research further depicted the modal shift effects after converting a general lane to a bus lane and quantified the impacts of bus share ratio on traffic operations under two scenarios (i.e. with and without bus lane) and accordingly identified the optimal bus share ratios under various travel demand levels, which have the potential to direct the installation of a dedicated bus lane such as the development of bus lane warrants.

Nevertheless, it is necessary to point out that in practice, the modal shift between two (or more) competitive traffic modes is a complex process. The expected modal share of bus passengers after the introduction of a dedicated bus lane depends on a number of factors such as level-of-service and cost (i.e. utility) of each mode, as well as the passengers origin-destination trip matrices on the analysed section. Converting a general lane to a bus lane would result in changes in the utilities of each mode, and accordingly, affect the passengers' mode choice behaviour [29, 30, 38, 39, 42]. With the identified optimal bus share ratios, the future research needs to develop Transportation Demand Management (TDM) strategies, such as congestion pricing, restrictions on the use of cars, subsidies to reduce the costs of bus fares, etc., to intervene the passengers' 
mode choice behaviour, and eventually, reach and maintain the desired bus share ratio that can maximize the operational performance of a corridor.

\section{CONCLUSION}

This paper has presented an analytical framework for modelling the effects of converting a general lane to a bus lane in corridor traffic operation and employed microsimulation modelling to assess traffic operations under various demand levels and bus share ratios. The relationship between bus share ratio and the total traffic volume of the roadway system was derived, which was employed for estimating the travel time and delay of each mode as well as the average passenger delay of the corridor. The simulation results indicate that converting a general lane to a bus lane significantly affected the operations of bus traffic and car traffic. For bus traffic, significant reductions in delay were found for all the demand levels; in comparison, for car traffic, the overall trend was that delay increased after converting a general lane to a bus lane. In addition, it was found that under all the tested scenarios, both average vehicle delay and average passenger delay decreased with the increase of bus share ratio, for both, with and without bus lane scenarios. For each demand level, when bus share ratio reached a certain level, the difference in delay with and without bus lane was no longer significant. The simulation results suggested that when demand is between 6,000 to $10,000 \mathrm{pph}$, a 60 percent bus share ratio would reach the equilibrium of delay (i.e. delay under no bus lane scenario equals the one with bus lane scenario); when demand is between 10,000 to $14,000 \mathrm{pph}$, the equilibrium bus share ratio increased to 80 percent.

\section{ACKNOWLEDGEMENTS}

This research has been partially sponsored by the China Ministry of Education of Humanities and Social Science, Grant No. 19YJCZH007.

\section{杨广川, 博士 ${ }^{1}$}

电子邮箱: yanggc1986@gmail.com

王道斌, 博士 ${ }^{2}$

（通讯作者）电子邮箱: wangdaobin05@163.com 毛雪松, 博士 ${ }^{3}$

电子邮箱: xsmao@wust.edu.cn

1 北卡罗来纳大学交通研究与教育所,

美国北卡罗来纳州罗利市Capability路909号

2 武汉科技大学汽车与交通工程学院,

中国湖北省武汉市和平大道947号

3 武汉科技大学信息科学与工程学院,

中国湖北省武汉市和平大道 947 号

\section{考虑出行方式转移的公交专用道影响分析}

\section{摘要}

本文提出了一种考虑出行方式转移的公交专用道 影响分析模型。该模型假设在给定的总出行量情况 下，道路实际交通量会随着私人汽车和公交车出行 方式的转移而改变。出行方式的动态转移会影响两 种出行方式的服务水平; 最终, 两种出行方式的比 例会达到一个平衡点以实现道路系统最优。随后, 本文采用微观仿真验证了不同出行量和公交车出行 比例条件下的道路运行情况。仿真结果显示设置公 交专用道能明显降低公交车延误，但同时增大了私 人交通出行延误; 此外, 延误与公交出行比例呈负 相关关系。然而, 当公交出行比例达到 $60 \%$ （假设 总出行量为 10,000 人次每小时), 设置公交专用道 并无明显地降低总出行延误 (当总出行量为 14,000 人次每小时，对应的公交出行比例为 $80 \%$ ）。这些 最优公交出行比例可以为制定公交专用道的设置条 件提供一定的理论依据。此外, 本文建议后续研究 从交通规划角度定量分析相关交通需求管理及公交 优先政策以促进出行方式向最优公交比例转移。

关键词

公交专用道; Mogridge猜想; 出行方式转移; 微观仿真；延误；公交专用道设置阈值

\section{REFERENCES}

[1] Mesbah M, Sarvi M, Currie G, Saffarzadeh M. Policy-Making Tool for Optimization of Transit Priority Lanes in Urban Network. Transportation Research Record. 2010;2197: 54-62.

[2] Idris AO, Habib KMN, Shalaby A. Dissecting the Role of Transit Service Attributes in Attracting Commuters: Lessons from a Comprehensive Revealed Preference-Stated Preference Study on Commuting Mode-Switching Behavior in Toronto, Ontario, Canada. Transportation Research Record. 2014;2415: 107-117.

[3] Idris AO, Habib KMN, Shalaby A. An Investigation on the Performances of Mode Shift Models in Transit Ridership Forecasting. Transportation Research Part A. 2015;78: 551-565.

[4] Anwar AM, Yang J. Examining the Effects of Transport Policy on Modal Shift from Private Car to Public Bus. Procedia Engineering. 2017;180: 1413-1422.

[5] Fearnley N, Flugel S, Killi M, et al. Triggers of Urban Passenger Mode Shift - State of the Art and Model Evidence. Transportation Research Procedia. 2017;26: 6280.

[6] Rahman ML, Baker D. Modelling Induced Mode Switch Behaviour in Bangladesh: A Multinomial Logistic Regression Approach. Transport Policy. 2018;71: 81-91.

[7] Sheffi Y. A Simple Equilibrium Analysis of Designating a Freeway Lane to Exclusive Bus Use. Transportation Research Record. 1981;775: 7-11.

[8] Mogridge MJH. The Self-defeating Nature of Urban Road Capacity Policy. Transport Policy. 1997;4(1): 5-23. 
[9] Hounsell N, McDonald M. Evaluation of Bus Lanes. Transport and Road Research Laboratory, U.K. Report Number: 87, 1988.

[10] Shalaby S, Soberman M. Effect of With Flow Bus Lanes on Bus Travel Times. Transportation Research Record. 1994;1433: 25-30.

[11] St. Jacques K, Levinson H. Operational Analysis of Bus Lanes on Arterials. Transportation Research Board, Transit Cooperative Research Program 26, Washington, D.C., 1997.

[12] Gibson J, Munizaga MA, Schneider C, Tirachini A. Estimating the Bus User Time Benefits of Implementing a Median Busway: Methodology and Case Study. Transportation Research Part A. 2016;84(5): 72-82.

[13] Truong LT, Currie G, Sarvi M. Analytical and Simulation Approaches to Understand Combined Effects of Transit Signal Priority and Road-Space Priority Measures. Transportation Research Part C. 2017;74: 275-295.

[14] Yao J, Cheng Z, Shi F, An S, Wang J. Evaluation of Exclusive Bus Lanes in a Tri-Modal Road Network Incorporating Carpooling Behavior. Transport Policy. 2018;68: 130-141.

[15] Currie G, Sarvi M, Young, B. A New Approach to Evaluating On-Road Public Transport Priority Projects: Balancing the Demand for Limited Road-Space. Transportation. 2007;34(4): 413-428.

[16] Gan A, Yue H, Ubaka I, Zhao F. Development of Operational Performance and Decision Models for Arterial Bus Lanes. Transportation Research Record. 2003;1858: 18-31.

[17] Tsamboulas D. Ex-Ante Evaluation of Exclusive Bus Lanes Implementation. Journal of Public Transportation. 2006;9(3): 201-217.

[18] Mesbah M, Sarvi M, Currie, G. New Methodology for Optimizing Transit Priority at the Network Level. Transportation Research Record. 2008;2089: 93-100.

[19] Li S, Ju Y. Evaluation of Bus-exclusive Lanes. IEEE Transactions on Intelligent Transport System. 2009;10(2): 236-245.

[20] Yao J, Shi F, Zhou Z, Qin J. Combinatorial Optimization of Exclusive Bus Lanes and Bus Frequencies in Multi-Modal Transportation Network. Journal of Transportation Engineering. 2012;138(12): 1422-1429.

[21] Zhao J, Zhou X. Improving the Operational Efficiency of Buses with Dynamic Use of Exclusive Bus Lane at Isolated Intersections. IEEE Transactions on Intelligent Transportation Systems. 2019;20(2): 642-653.

[22] Shalaby A. Simulating Performance Impacts of Bus Lanes and Supporting Measures. Journal of Transportation Engineering. 1999;125(5): 390-397.

[23] Waterson BJ, Rajbhandari B, Hounsell NB. Simulating the Impacts of Strong Bus Priority Measures. Journal of Transportation Engineering. 2003;129(6): 642-647.

[24] Arasan VT, Vedagiri P. Microsimulation Study of the Effect of Exclusive Bus Lanes on Heterogeneous Traffic Flow. Journal of Urban Planning and Development. 2010;136(1): 50-58.

[25] Zhu L, Yu L, Chen X, Guo J. Simulated Analysis of Exclusive Bus Lanes on Expressways: Case Study in Beijing, China. Journal of Public Transportation. 2012;15(4): 111-128.

[26] Tu TV, Sano K, Nguyen CY, Tan DT. Comparative Analysis of Bus Lane Operations in Urban Roads using Microscopic Traffic Simulation. Asian Transport Studies. 2013;2(3): 269-283.

[27] Ben-Dor G, Ben-Elia E, Benenson I. Assessing the Impacts of Dedicated Bus Lanes on Urban Traffic Congestion and Modal Split with an Agent-Based Model. Procedia Computer Science. 2018;130: 824-829.

[28] Ben-Akiva M, Lerman S. Discrete Choice Analysis: Theory and Application to Travel Demand. Cambridge, MA: MIT Press; 1985.

[29] Sheffi Y. Urban Transportation Networks: Equilibrium Analysis with Mathematical Programming. Englewood Cliffs, NJ: Prentice-Hall Inc.; 1985.

[30] Sun H, Si B, Wu J. Combined Model for Flow Assignment and Mode Split in Two-Modes Traffic Network. Journal of Transportation Systems Engineering and Information Technology. 2008;8(4): 77-82.

[31] Zuo Z, Yang G, Shao C. Modeling Modal Shift of Car Travelers to Buses Based on Public Transport Priority. Journal of Transportation Systems Engineering and Information Technology. 2011;12(1): 124-131.

[32] Vedagipi P, Arasan V. Modelling Modal Shift Due to the Enhanced Level of Bus Service. Transport. 2009;24(2): 121-128.

[33] Zuo Z, Yang G, Shao C. Modal Shift of Car Travelers to Buses Based on Bus Priority. Proceedings of $91^{\text {st }}$ Annual Meeting of Transportation Research Board, Washington D.C.; 2012.

[34] Wang Y, Wang Z, Li Z, Staley SR, Moore AT, Gao Y. Study of Modal Shifts to Bus Rapid Transit in Chinese Cities. Journal of Urban Planning and Development. 2013;139(1): 515-523.

[35] Wang Y, Li L, Wang Z, Lv T, Wang L. Mode Shift Behavior Impacts from the Introduction of Metro Service: Case Study of Xi'an, China. Journal of Transportation Engineering. 2013;139(3): 216-225.

[36] Yao J, Shi F, An S, Wang J. Evaluation of Exclusive Bus Lanes in a Bi-Modal Degradable Road Network. Transportation Research Part C. 2015;60: 35-16.

[37] Zheng N, Dantsuji T, Wang P, Geroliminis N. Macroscopic Approach for Optimizing Road Space Allocation of Bus Lanes in Multimodal Urban Networks Through Simulation Analysis. Transportation Research Record. 2017;2651: 42-51.

[38] Downs A. The Law of Peak-Hour Expressway Congestion. Traffic Quarterly. 1962;16(3): 393-409.

[39] Mogridge M, Holden D, Bird J, Terzis G. The Downs-Thomson Paradox and the Transportation Planning Process. International Journal of Transportation Economics. 1987;14(3): 283-311.

[40] Meneguzzer C. Review of Models Combining Traffic Assignment and Signal Control. Journal of Transportation Engineering. 1997;123(2): 148-155.

[41] Gartner N, Al-Malik, M. Combined Model for Signal Control and Route Choice in Urban Traffic Networks. Transportation Research Record. 1996;1554: 27-35. 
[42] Wardrop JG. Some Theoretical Aspects of Road Traffic Research. Proceedings of Institution of Civil Engineers, Part II. 1952;1(2): 325-378.

[43] Yang H, Yagar S. Traffic Assignment and Signal Control in Saturated Road Networks. Transportation Research Part A. 1995;29(2): 125-139.

[44] Mazloumi E, Moridpour S, Mohsenian H. Delay Function for Signalized Intersections in Traffic Assignment Models. Journal of Urban Planning and Development. 2010;136(1): 67-74.

[45] TRB. Highway Capacity Manual, Sixth Edition: A Guide for Multimodal Mobility Analysis. Washington, D.C.: The National Academies of Sciences, Engineering, and Medicine; 2016. 